\title{
Technology platform for customized ceramic sensors for gases, temperatures and flows - Innovative gas sensors for selected applications in safety and medical engineering -
}

\author{
Dr.-Ing. Olaf Kiesewetter, Nils Kiesewetter, Alexander Kraußer, Christian Loos, Matthias May \\ UST Umweltsensortechnik GmbH, Dieselstr. 2, 98716 Geschwenda, Germany, \\ info@umweltsensortechnik.de
}

\begin{abstract}
:
Ceramic sensors are used to measure gas concentrations, temperatures, flow and other parameters in many fields of application, such as industrial process measurement, automotive electronics, building automation, energy engineering, environmental technology, safety engineering and medical engineering. Based on a brief description of the functional principles and the design of MOX gas sensors and platinum temperature sensors, a technology platform for the production of ceramics sensor elements will be described. Innovative gas sensor systems for two selected applications in the fields of medical and safety engineering will be briefly described.
\end{abstract}

Key words: Gas sensor,Temperature sensor,Electronic nose,Medical engineering,Safety engineering

\section{Platinum thin-film temperature sensors}

The functionality of Platinum temperature sensors is based on the dependence of the electrical resistance of the Platinum from the temperature. A Platinum temperature sensor is designated by its nominal resistance at a temperature of $0{ }^{\circ} \mathrm{C}$ (e.g. Pt100.. R $0=100 \mathrm{Ohm}$, Pt1000... R0 $=10000 \mathrm{hm})$. With increasing temperature the resistance increases, with decreasing temperature the resistances decreases. The characteristic of Platinum temperature sensors is defined in DIN EN 60751. Platinum temperature sensors are realized in various technologies. Fig. 1 shows a wired Platinum temperature sensor element, realized in advanced thin-film-technology (ceramic carrier with a structured platinum layer, covered with a passivating layer).

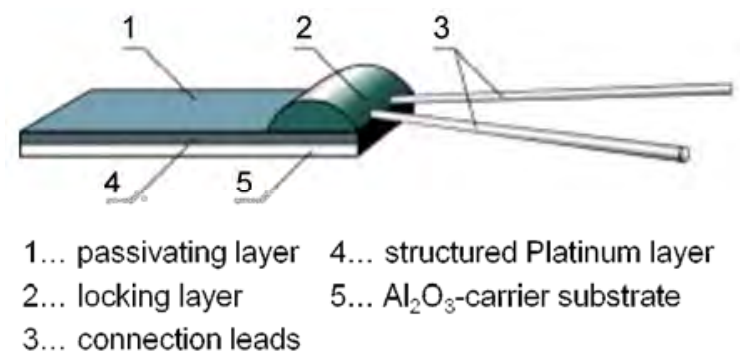

Fig. 1: Platinum thin-film temperature sensor element

\section{MOX Gas sensor elements}

Fig. 2 shows MOX gas sensor elements produced in hybrid technology.

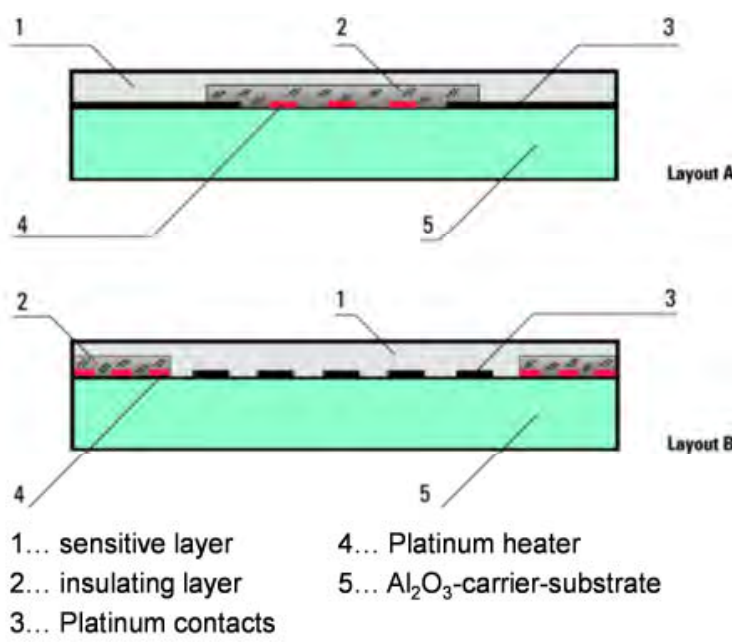

Fig. 2: Structural design of MOX gas sensor elements

The functionality of MOX gas sensors is based on the changes in conductivity of the sensitive semi-conductor layer when exposed to gases. The heater resistance has a defined temperature coefficient, which permits the control of the working temperature of the 
sensor. This allows the compensation of varying ambient temperatures and permits defined influence of the sensitivity of the sensor. The gas sensor reacts to oxidized (increase of the resistance of the sensitive layer) and reducible gases (decrease of the resistance of the sensitive layer). The detection range (from a few ppb to 5 vol. \%) depends on the sensor type and on the gas.

\section{Technology platform}

These gas and temperature sensors are produced on a common technology platform. Essential elements of the technology platform are:

- scalable modular system of structures for functional elements for the platinum micro structuring of the sensor elements (electrodes, meander and contact pads);
- validated sensor materials: ceramic substrates $\left(\mathrm{Al}_{2} \mathrm{O}_{3}\right)$, Platinum, special glasses for insulation, passivation and protection layers, leads;

- validated technological process steps for coating, micro structuring, thermal processes, bonding and chip tests etc.;

- reliable adequate process technology and equipment for gas and platinum temperature sensor elements.

For the micro structuring two technologies are used - structuring by solid state laser and photolithographic structuring. With photolithographic structuring the sensor elements can be produced more efficiently in particular in large series. Additionally smaller chip dimensions (e.g. Pt1000/chip area $1 \mathrm{~mm}^{2}$, Pt10000/chip area appr. $4 \mathrm{~mm}^{2}$ ) are realizable. Fig. 3 shows an overview of the sensor element technology.

Laser process

Photolithographic process

Platinum temperature sensor elements + gas sensor elements Platinum temperature sensor elements + gas sensor elements

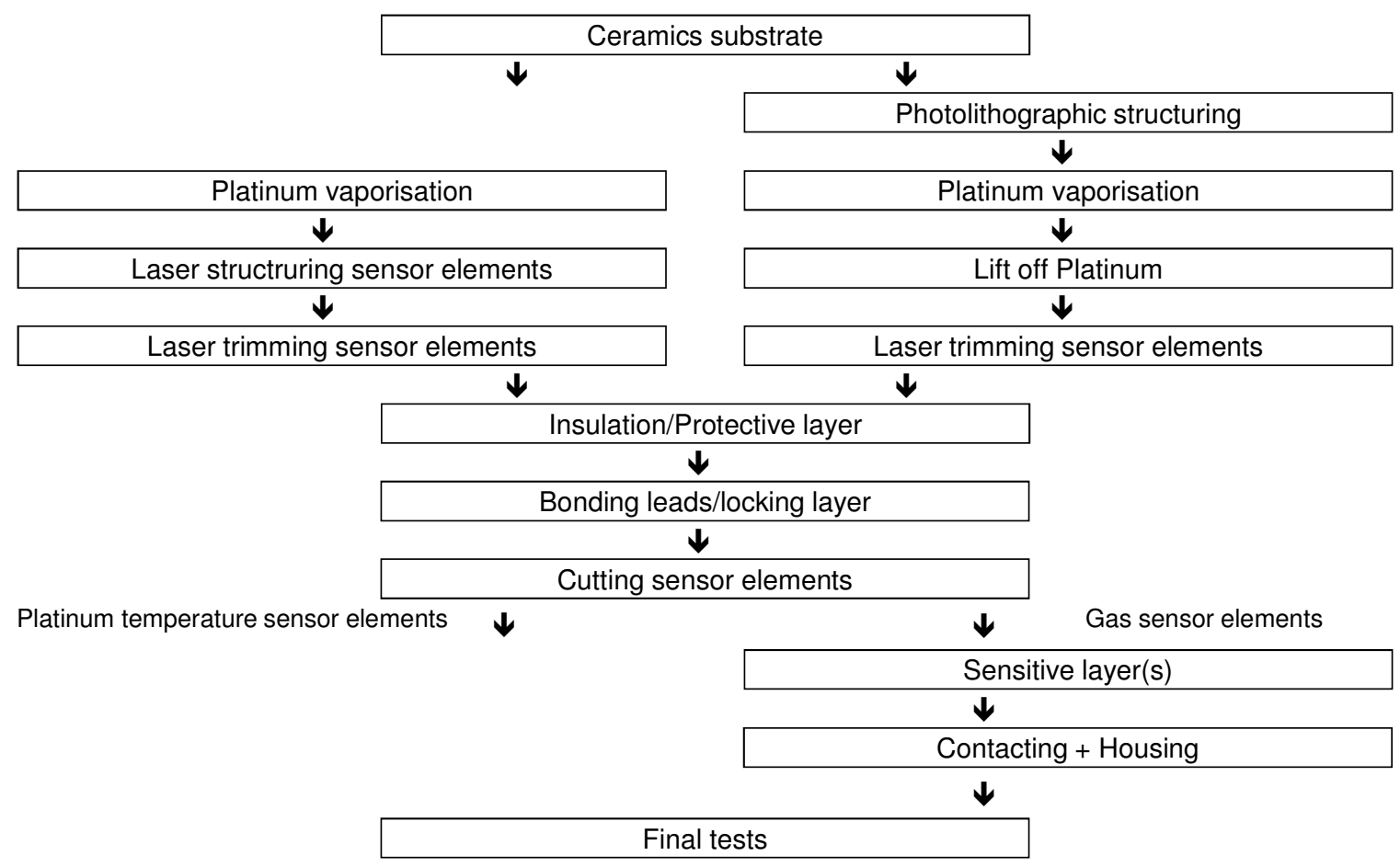

Fig. 3: Technology for ceramic sensor elements

\section{Innovative MOX gas sensor system in medical engineering}

Subproject of the joint research project "Recognition of cardiac disease using an electronic nose (JEENA)", was the development of a demonstrator for an innovative gas sensor module for the detection of gaseous, emitting metabolites on the human skin and in the breathing air (Fig: 4). 


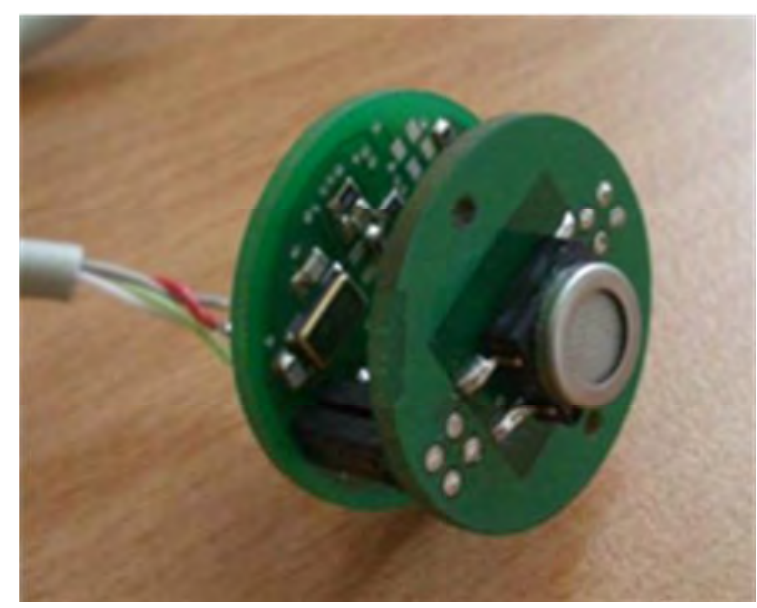

Fig. 4: JEENA-Gas sensor module (Demonstrator)

The demonstrator of the developed gas sensor module is based on the technology of the patented UST Triplesensor ${ }^{\circledR}$.
Compared to single, double gas sensor elements or arrays the UST Triplesensor ${ }^{\circledR}$ gas sensor module consists of a ceramic semiconductor gas sensor element with three different gas sensitive layers for reducible, highly and hardly oxidable gases on the same ceramics substrate within a 4-pin-housing as well as an electronic module for the control of the sensor element, the storage of calibration data, signal pre-processing and data communication.

An application-specific control of the sensor element and signal processing allows the high sensitive detection of specific gases or gas mixtures in a range from only a few ppm up to several Vol\% and, afterwards, its external classification and quantitative analysis.

Fig. 5 and Fig. 6 show exemplary the separation of the gases $\mathrm{NO}_{2}, \mathrm{H}_{2}$ and $\mathrm{NH}_{3}$.

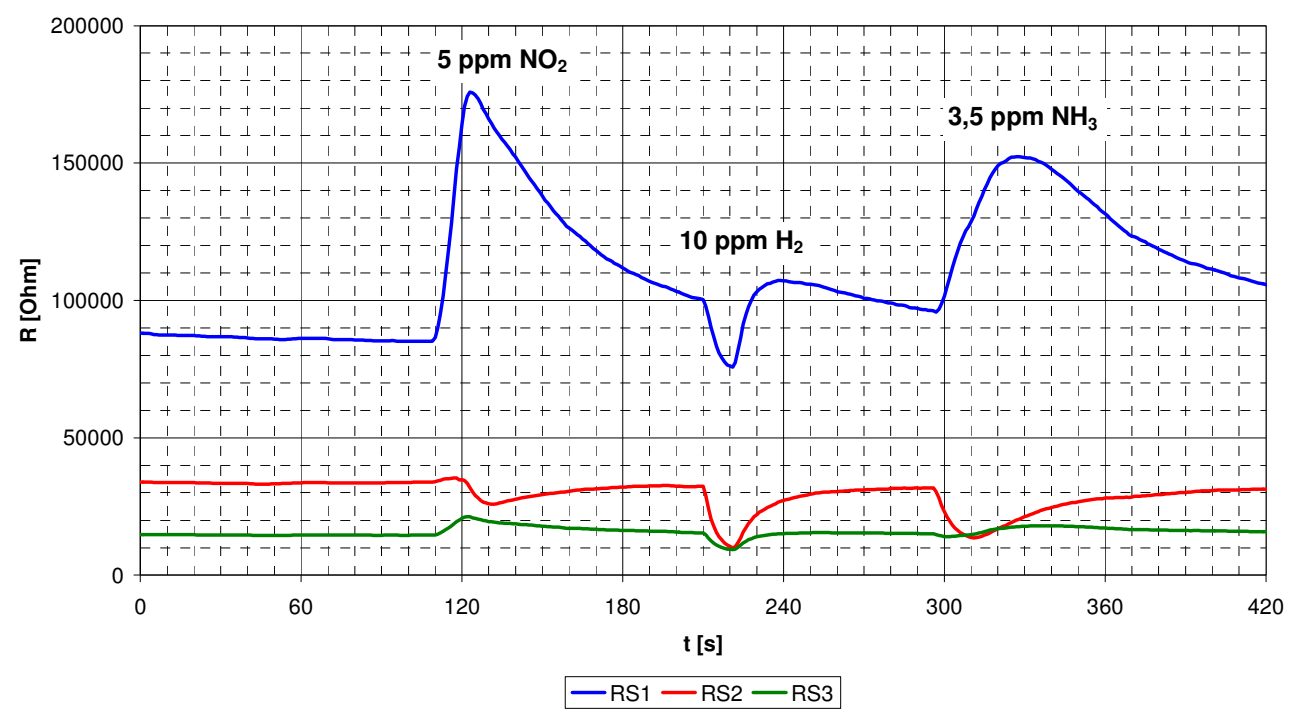

Fig. 5: UST Triplesensor ${ }^{\circledR}$ - separation of gases - raw values of the layer resistances

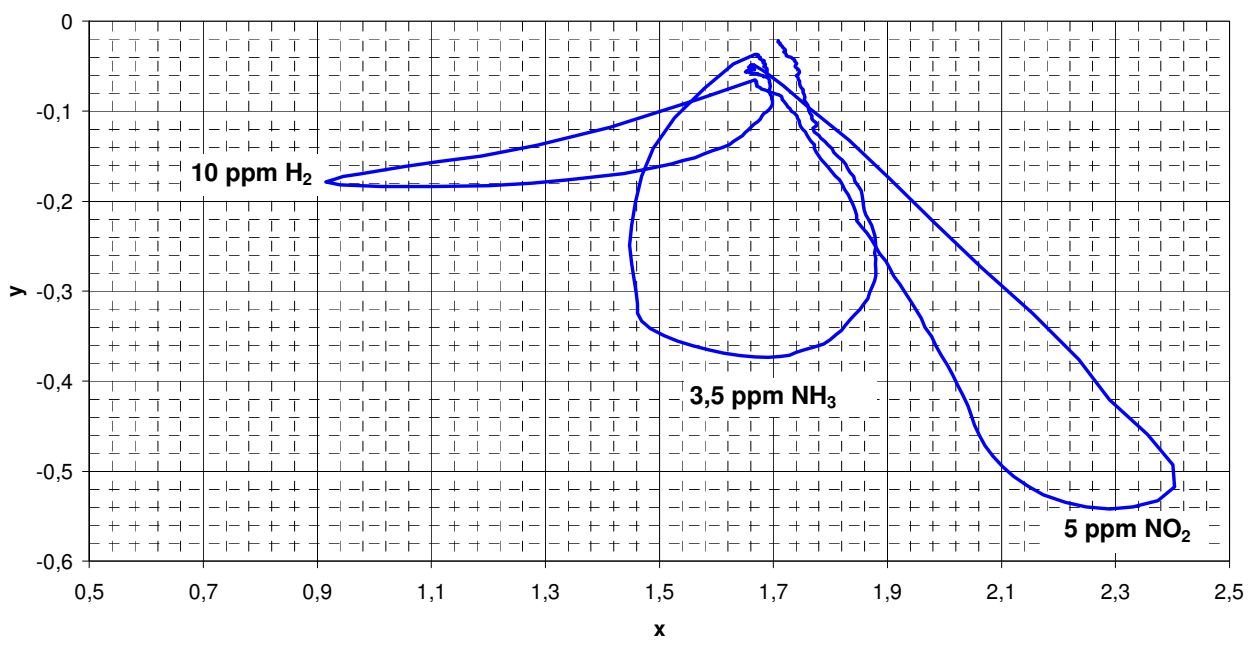

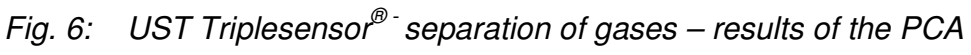


By means of the hardware and software modularity and variability in combination with the wide range of selectivity and sensitivity, the UST Triplesensor ${ }^{\circledR}$ provides a technological platform for the realization of cost-efficient, application-specific gas sensor systems scalable from small batch to high volume series.

Typical fields of application exist in process engineering, building automation, power and environmental engineering, automotive industry, medical engineering, logistics and transport. Particular applications are, for instance, the early detection of smouldering fires, the detection of selected VOC markers and refrigerants, the gas leak detection at natural gas connections as well as the measurement of the air quality.

Key features of the "JEENA" gas sensor module are a new "chip"-structure (FU10H11) with $\mathrm{Y}$-connection for the sensitive layers and different sensitive layers for gases, gas mixtures and humidity, which are applicationspecific customizable (Fig. 7 and Fig. 8).

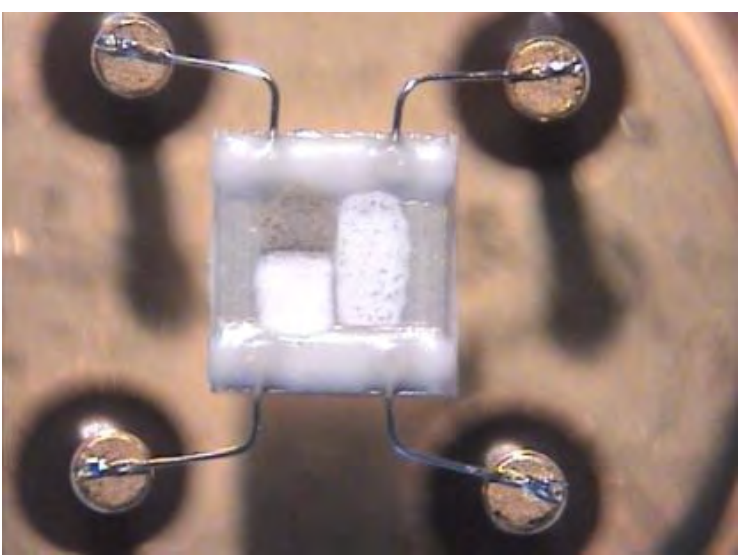

Fig. 7: UST Triplesensor ${ }^{\circledR}$ Gas sensor element FU10H11

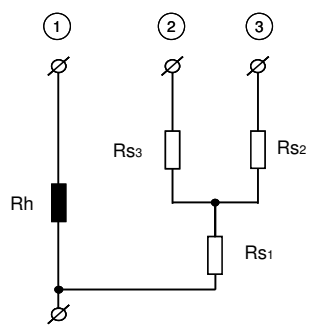

(4)

Fig. 8: UST Triplesensor ${ }^{\circledR}$ Gas sensor element FU10H11 - $Y$-connection of the sensitive-layerresistances $R_{S 1-3},\left(R_{H} \ldots\right.$ Heater resistance)

Compared to series or delta circuits the $\mathrm{Y}$ connection/star circuit allows highly different dimensions of the resistance values of the sensitive layers. An adaption or a reduction of the measurement voltage is possible. Advantages compared to other circuit variants are e.g. direct, relatively simple resistance calculation, a high accuracy in resistance measurement and calculation and the heating voltage induces only low interferences.

An innovative isothermic sensor housing (SMD) allows the realization of replaceable sensor heads. The electronics allows custom factory calibration for JEENA application.

The gas sensor module is applicated in demonstrators of a skin applicator and a breath adapter of an industrial partner in the JEENA project. This technology provides also the future potential for detection of substances on the skin or in breath which are relevant for other diseases etc.

\section{Innovative MOX Gas sensor system for rotary dryers for wood particles}

In a subproject of the Joint research project "Drying of wood particles optimized by Bionics (BIOHOT)" a demonstrator for a gas sensor system for the early detection of fire relevant volatiles a. o. during the drying process of wood particles was developed (Fig. 9).

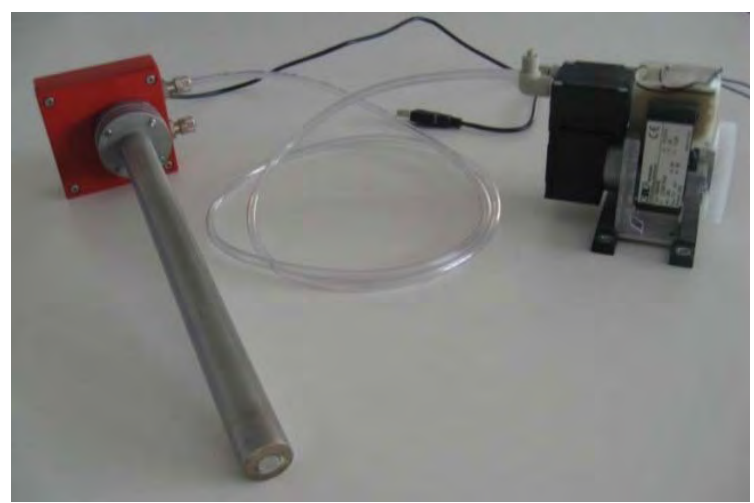

Fig. 9: $\quad$ Gas sensor system (demonstrator) for using in rotary dryers for wood particles

The gas sensor system is also based on UST Triplesensor $^{\circledR}$ gas sensor technology and detects volatiles for early fire detection and combustion gases in rotary dryers for wood particles. The gas sensor element is integrated in an isothermic sensor housing with inner and outer cooling channels for customized adaptation and optimization of the sensor by controlling or reversing the cooling air flow. An integrated special filter protects the senor against drop formation, particles etc. The isothermic sensor housing is mounted on a certified housing for the sensor electronics.

In the frame of tests of the demonstrator wood chips were heated in a converter up to $400^{\circ} \mathrm{C}$. During the heating and the combustion process emerging relevant different substances at the individual temperature ranges were detected (Fig. 10-12). 


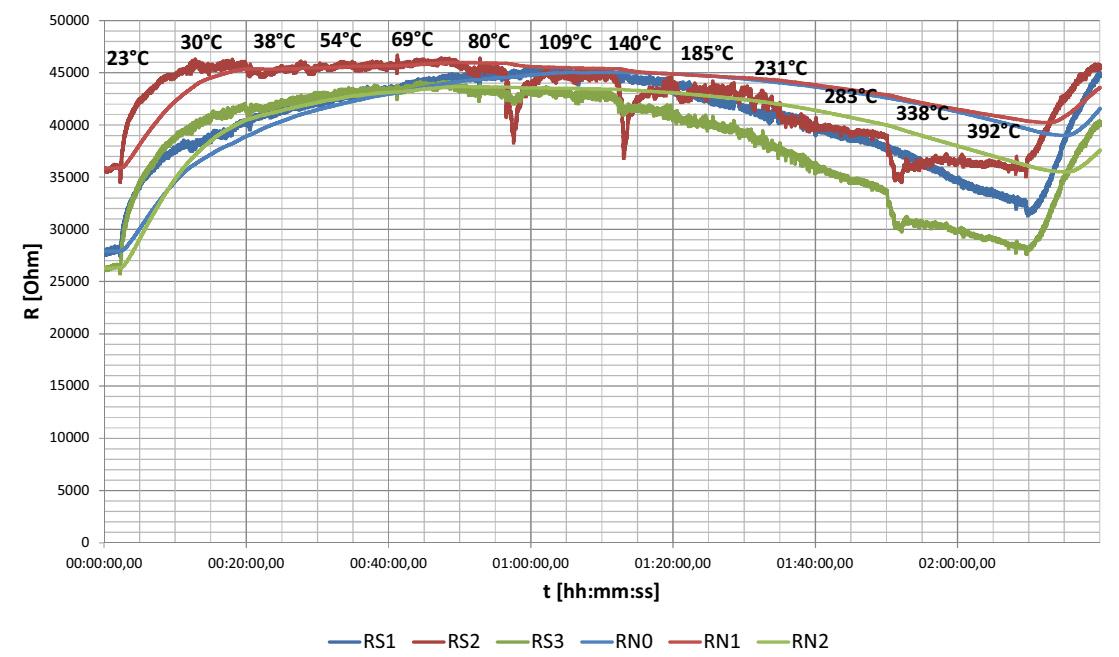

Fig. 10: BIOHOT - Demonstrator gas sensor system - resistance curve with tracked temperature profile from $20^{\circ} \mathrm{C}$ up to $400^{\circ} \mathrm{C}$ - changes á 10 minutes (RS1-3... layer resistances, RNO-2... resistance values tracking)

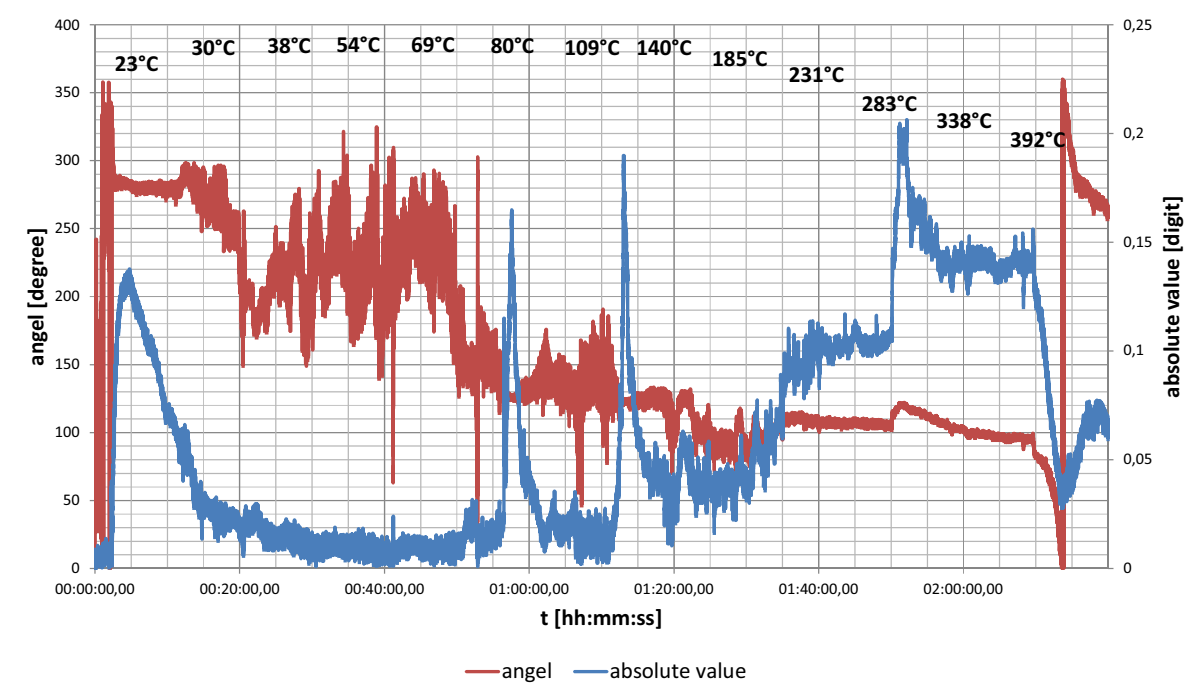

Fig. 11: BIOHOT - Demonstrator gas sensor system - absolute value and angle on temperature profile (from $20^{\circ} \mathrm{C}$ up to $400^{\circ} \mathrm{C}$ - changes á 10 minutes)

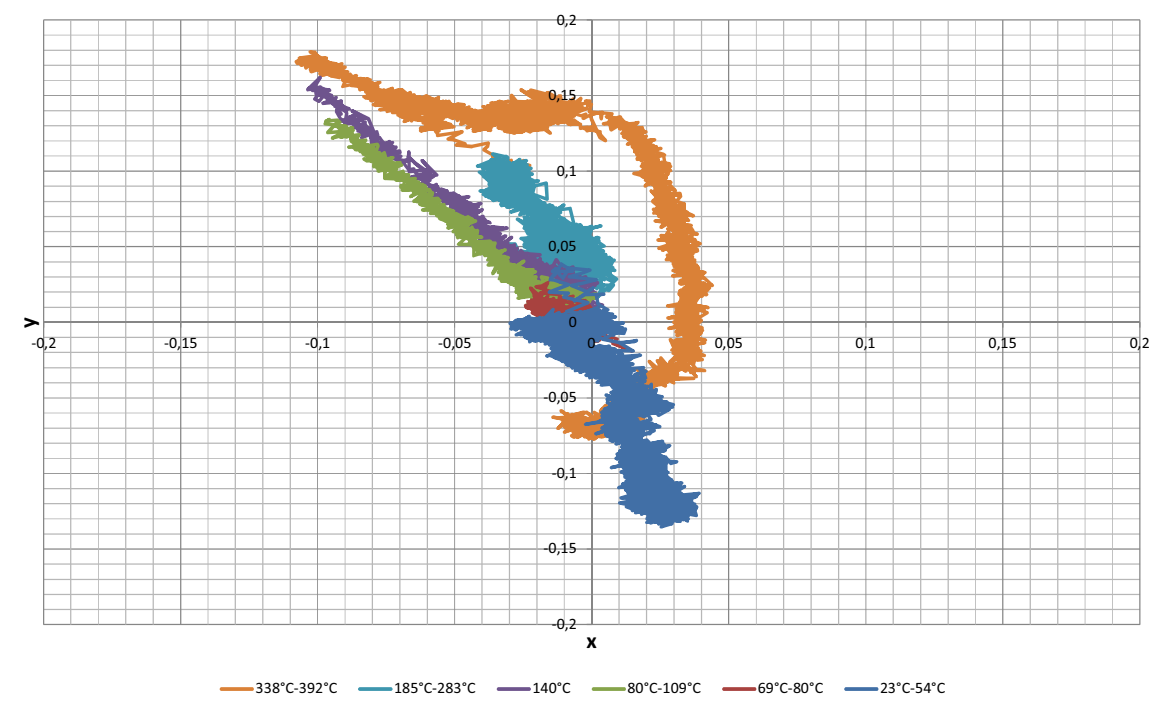

Fig. 12: BIOHOT - Demonstrator gas sensor system - graphical 2D-PCA (y on $x$ ) 
In Fig. 12 the green area represent substances occured in a temperature range from $80^{\circ} \mathrm{C}$ up to $109^{\circ} \mathrm{C}$, the purple area - substances occured at appr. $140^{\circ} \mathrm{C}$, the orange area - substances occured in a temperature range from appr. $338^{\circ} \mathrm{C}$ up to $392^{\circ} \mathrm{C}$ and the cyan area substances occured in a temperature range from appr. $185^{\circ} \mathrm{C}$ up to $283^{\circ} \mathrm{C}$.

The blue and red area represent the start phase of the heating process. The signals of the green, purple and orange areas will be relevant for the following signal processing and control of the drying process. From a drying temperature of appr. $300^{\circ} \mathrm{C}$ fire relevant decomposition products will be occurred, which are detectable with the described gas sensor system.

The using of the gas sensor system in the drying process allow

- to increase the drying process safety in woodworking (prevent downtime due to fires in the dryer);

- to have an higher efficiency of the drying process by optimizing the process control (higher drying temperature $\rightarrow$ acceleration of the drying process);

- to save energy and therefore fuel in the drying processes in order.

\section{Summary}

The described technology platform for customized ceramic sensor elements allows the flexibly and efficiently production of customized MOS gas sensor elements, platinum thin-film temperature sensor elements as well as flow sensor elements (according to the principle of the thermal anemometer) in the highest quality from small up to large series.

From the viewpoint of the authors future opportunities for the described sensor technologies include sensor elements, sensors and sensor systems (gases, temperatures, flows, ...) for

- safety-related applications (early fire detection, detection of hazardous substances, presence detection, ...);

- the detection of selected VOC markers, gas mixtures etc. (air quality, breath, ...);

- measurement and control systems;

- applications with a high level of sustainable energy and resource efficiency; especially in fields of application such as automotive, process engineering, building automation, energy and environmental technology, logistics (transport and storage), medical engineering and food technology.

\section{References}

[1] DIN EN 60751:2009-05: Industrielle PlatinWiderstandsthermometer und PlatinTemperatursensoren (IEC 60751:2008); Deutsche Fassung EN 60751:2008, Beuth Verlag $\mathrm{GmbH}, 2009$

[2] Kiesewetter, Olaf; Ewert, Anatolij; Melchert, Volkmar; Kittelmann, Sven (Inventors), UST Umweltsensortechnik GmbH, Geschwenda (Patentee), „Anordnung zur Detektion von Luftinhaltsstoffen und Verfahren zum Betreiben der Anordnung", Deutsches Patent, Nr. DE102004060101 B4, 13.12.2004

[3] Kittelmann, Sven; Ewert, Anatolij; Kiesewetter, Olaf (Inventors), UST Umweltsensortechnik $\mathrm{GmbH}$, Geschwenda (Patentee), ,Anordnung zur Detektion von Luftinhaltsstoffen“, Deutsches Patent, Nr. DE 102006033528 B3, 20.07.2006

[4] Kiesewetter, Olaf; Ewert, Anatolij; Melchert, Volkmar; Kittelmann, Sven (Inventors), UST Umweltsensortechnik GmbH, Geschwenda (Patentee), „Assembly for detecting air components", European Patent, No. EP 1602924 B1, 02.06.2005

[5] Schütz, Stefan; Gabriel, Martin; Paczkowski; Sebastian; Paczkowska, Marta; Kohl, ClausDieter; Bauer, Marco; Weiß, Alexander; Kiesewetter, Olaf; May, Matthias; Kraußer, Alexander; Hertel, Thomas, Entwicklung eines sensorgestützten Produktionsoptimierungsprozesses auf der Basis der Informationsverarbeitung der Antenne von Melanophila acuminata zum Nachweis von freiwerdenden organischen Volatilen aus trocknenden Holzpartikeln, BMBF, Project Numbers 01RB0804A-C, Final report/Schlussbericht, 2012, Private communication

[6] Kiesewetter, Olaf; Bauer, Marco, „Gas sensors for wood drying and combustion processes", Lecture, European Conference on The Future of Gas Sensors for Fire Detection and Safety Techniques, 5th/6th September 2012, Saarbrücken, Germany

[7] Kiesewetter, Olaf, UST Umweltsensortechnik $\mathrm{GmbH}$, Geschwenda, Lectures and Presentations 2005-2013, Private communication 